\title{
Effect of porous structure on doping and the catalytic performance of carbon xerogels towards the oxygen reduction reaction
}

Maria Canal-Rodríguez ${ }^{\mathrm{a}}$, Natalia Rey-Raap ${ }^{\mathrm{b} *}$, J. Ángel Menéndez ${ }^{\mathrm{a}}$, Miguel A. MontesMorán $^{\mathrm{a}}$, José Luis Figueiredo ${ }^{\mathrm{b}}$, Manuel Fernando R. Pereira ${ }^{\mathrm{b}}$, Ana Arenillas ${ }^{\mathrm{a} *}$

${ }^{a}$ Instituto Nacional del Carbón, INCAR-CSIC, Francisco Pintado Fe 26, 33011 Oviedo, Spain

${ }^{b}$ Associate Laboratory LSRE-LCM, Departamento de Engenharia Química, Faculdade de Engenharia, Universidade do Porto, R. Dr Roberto Frias s/n, 4200-465 Porto, Portugal

*Corresponding authors: NRR (nataliarey@fe.up.pt) and AA (aapuente@incar.csic.es $))$

\begin{abstract}
The development of new electrocatalysts based on carbon materials lies in the appropriate design of their physicochemical properties. The porous structure of the carbon xerogels is expected to have a direct effect on the subsequent processes used to further design the properties. Hence, it is essential to understand how the porous structure can affect the efficiency of the doping method and change their catalytic performance. To this end, carbon xerogels with different micropore volumes and electrical conductivities were prepared by applying different heat treatments (carbonization, activation and graphitization) to a macroporous organic xerogel synthesized by microwave heating. Nitrogen functionalities and iron nanoparticle were introduced into the carbonaceous structures. Doped and un-doped materials were tested as electrocatalysts for the oxygen reduction reaction. The amount of nitrogen introduced into the carbon structure decreases with the degree of order, while the type of nitrogen functional groups depends on the porous structures: higher volume of micropores allows the incorporation of quaternary nitrogen. Catalytic sites are mainly located in the micropores, macroporosity favours the
\end{abstract}


diffusion of the reactants, and nitrogen functionalities shift the mechanism of the reaction to the four-electron pathway. The addition of iron particles allows achieving the same performance than that of the platinum-based reference material.

Keywords: Carbon xerogel; nitrogen functionalities; iron nanoparticles; electrocatalyst; oxygen reduction reaction.

\section{Introduction}

The accessible fuel-deposits of the world are being depleted due to the constant increase in the consumption of fossil fuels. This fact has generated an interest in developing clean and sustainable energy conversion systems with high efficiency and low cost. Some of these devices, such as fuel cells or metal-air batteries, are based on electrochemical systems involving the oxygen reduction reaction (ORR) [1]. The ORR, which usually occurs at the cathode, is one of the main critical processes in these systems due to its sluggish reaction kinetics [2-4]. Several electrocatalysts have been developed trying to increase the electrochemical performance for the ORR, with platinum-based materials

supplying the fastest kinetics to date $[5,6]$. However, platinum electrocatalysts are costly and scarce, and thus, replacing platinum by a more economic material has become a major challenge. A great number of studies have been reported focused on the development of new electrocatalysts for the ORR. Such studies may be grouped in two main strategies: i) design of metal-free electrocatalysts $[1,3,7-12]$ or ii) reduce the amount of platinum by replacing it partially or totally by non-noble metals [4-6, 13-15].

The design of metal-free electrocatalysts has been mostly focused on the use of carbonbased materials, due to their high catalytic activity, cost-effectiveness, and durability [8, 14, 16-18]. The optimization of the electrocatalytic activity of carbon-based materials lies 
in the appropriate design of their physicochemical properties in order to have a high density of catalytically active sites fully accessible $[19,20]$. The number of active sites can be improved by combining a well-developed porosity and a high electrical conductivity $[14,18,19]$, and by the incorporation of surface functional groups, specifically nitrogen functionalities $[16,17,21-23]$. On the other hand, the replacement of platinum by non-noble metals has received much attention in the last years due to the higher activity and long-term stability in comparison with metal-free carbons $[13,15,21$, 24]. Cobalt and iron have shown to improve the electroactivity of carbon materials towards ORR, especially when the metals are coordinated to nitrogen $[2,6,15,21,25]$. However, the role and synergetic effect between porosity, heteroatoms, and metals on the ORR are still unclear, and more research is essential. Therefore, the use of carbon materials that can be easily tailored is an interesting strategy to study the combined effect between structural and chemical properties on the performance of carbon materials for ORR. In this context, carbon gels are excellent candidates, as their main properties can be easily tailored: porosity, electrical conductivity and surface chemistry. The meso/macroporosity of carbon gels can be designed by modifying the conditions of the synthesis process, while microporosity can be generated by subsequent carbonization/activation treatments [26-29]. In addition, carbonization and activation also induce the ordering of the carbonaceous framework, giving rise to carbon gels with a good electrical conductivity [30]. Besides, the electrical conductivity can be further enhanced by introducing conductive additives, such as graphene, carbon nanotubes or carbon black, into the carbon xerogel structure [31]; or by heating the carbon xerogel at graphitization temperatures (above $2000^{\circ} \mathrm{C}$ ) [32]. On the other hand, the modification of the surface chemistry of carbon materials is also possible using post-synthesis functionalization treatments $[7,12,18,20]$. Therefore, the appropriate combination of all 
these methods could result in carbon xerogels with excellent performance toward the ORR. However, the effect of one of the methods mentioned above may influence the impact of the other, greatly hampering the design of the adequate properties. It is due essential to understand how the porous structure of the carbon xerogels can alter the efficiency of the doping method and change their catalytic performance towards the ORR.

Therefore, this work aims to synthesize carbon xerogels by microwave heating with different physicochemical properties and to evaluate their performance as electrocatalysts for the ORR. To tackle it, in the present study an organic xerogel was subjected to different heat treatments (i.e., carbonization, activation, and graphitization) to obtain carbon xerogels with different volumes of micropores and electrical conductivities. Moreover, these xerogels were also subjected to a post-synthesis treatment with melamine in order to incorporate nitrogen into their carbonaceous structures. The quantity and nature of the nitrogen incorporated were evaluated in accordance with the properties of their respective precursors. Finally, iron particles were introduced into the most promising carbon structure and the relationship between the final properties and the ORR performance was evaluated.

\section{Experimental}

\subsection{Synthesis of materials}

An organic xerogel was synthesized by the polycondensation of resorcinol (R) (Indspec, 99.6\% purity) and formaldehyde (F) (Merck, 37\% aqueous solution), using deionized water (W) as solvent. Firstly, resorcinol is mixed with water until reaching a homogeneous solution. Formaldehyde was subsequently added and the mixture was kept under magnetic stirring until complete integration of all reactants. Finally, the $\mathrm{pH}$ was adjusted with a solution of $\mathrm{NaOH}$. The synthesis conditions selected to get a pore size of 
$100 \mathrm{~nm}$ were: i) a dilution ratio (D) of 9.7 (defined as the solvent/reactants molar ratio [29]), ii) a molar ratio (R/F) of 0.5 and iii) a $\mathrm{pH}$ of 5.8. Once the precursor solution was prepared, it was introduced in a microwave oven at $85^{\circ} \mathrm{C}$ for $5 \mathrm{~h}$ in which the gelation, curing and drying of the gel were performed. Different carbon xerogels were obtained by applying different treatments to the organic xerogel: (i) carbonization, (ii) activation and (iii) graphitization.

(i) Carbonization was performed at $750{ }^{\circ} \mathrm{C}$ under a $\mathrm{N}_{2}$ flow of $150 \mathrm{~cm}^{3} / \mathrm{min}$ in a horizontal tubular furnace using a quartz reactor. The heating rate and residence time were fixed at $50^{\circ} \mathrm{C} / \mathrm{min}$ and $1 \mathrm{~h}$, respectively $(\mathrm{CX}-750)$.

(ii) Activation was accomplished in a horizontal tubular furnace using a quartz reactor at $1000{ }^{\circ} \mathrm{C}$ for $2 \mathrm{~h}$ with a heating rate of $50{ }^{\circ} \mathrm{C} / \mathrm{min}$ and a $\mathrm{CO}_{2}$ flow of $50 \mathrm{~cm}^{3} / \mathrm{min}(\mathrm{AX}$ 1000).

(iii) Graphitization was carried out with an Ar flow of $2 \mathrm{dm}^{3} / \mathrm{min}$ at a maximum temperature of $2000^{\circ} \mathrm{C}$ in a XX. The heating rates selected were as follows: a) $50{ }^{\circ} \mathrm{C} / \mathrm{min}$ until $700^{\circ} \mathrm{C}$; b) $100^{\circ} \mathrm{C} / \mathrm{min}$ from 700 to $1000{ }^{\circ} \mathrm{C}$ and c) $25^{\circ} \mathrm{C} / \mathrm{min}$ from 1000 to $2000{ }^{\circ} \mathrm{C}$. The residence time at the maximum temperature was $2 \mathrm{~h}$ (GX-2000). The sample introduced into the graphitization oven was previously carbonized at $1000^{\circ} \mathrm{C}$.

The nomenclature used was $\mathrm{CX}, \mathrm{AX}$ and $\mathrm{GX}$ according to the treatment at which the sample was subjected (carbonization, activation or graphitization, respectively), followed by the temperature of treatment. After the treatment, all samples were ball-milled at XX for $\mathrm{XX}$ min and then dried at $80^{\circ} \mathrm{C}$ overnight.

The samples were further functionalized with nitrogen by mixing $40 \mathrm{wt} . \%$ of melamine with $60 \mathrm{wt} . \%$ of each carbon xerogel. The mixture was treated in a vertical oven under a $\mathrm{N}_{2}$ flow of $70 \mathrm{~cm}^{3} / \mathrm{min}$, a heating rate of $10{ }^{\circ} \mathrm{C} / \mathrm{min}$ up to $700{ }^{\circ} \mathrm{C}$ and maintained at the 
maximum temperature for $2 \mathrm{~h}$. The samples were labelled as CX-750N, AX-1000N and GX-2000N.

In addition, sample $\mathrm{AX}-1000 \mathrm{~N}$ was also doped by the incipient wetness impregnation with a suspension of iron (II) phthalocyanine, FePc, (97 wt.\%) in ethanol. The activated sample (99 wt.\%) was added to the solution and then ultrasonicated during $1 \mathrm{~h}$. The mixture was dried overnight at $80{ }^{\circ} \mathrm{C}$ for complete removal of the solvent. The sample obtained was labelled as AX-1000NFe.

A commercial platinum-based electrocatalyst (20 wt.\% Pt on carbon black, HISPEC 3000 by Alfa Aesar) was also used for comparative purposes.

\subsection{Structural and chemical characterization}

The porosity of the samples was evaluated by nitrogen adsorption-desorption isotherms at $-196^{\circ} \mathrm{C}$ (Micromeritics Tristar 3020). The specific surface area $\left(\mathrm{S}_{\mathrm{BET}}\right)$ and the volume of micropores $\left(\mathrm{V}_{\text {micro }}\right)$ were calculated applying to the adsorption branch of the isotherms the equations of Brunauer-Emmett-Teller (BET) and Dubinin-Radushkevich (DR), respectively. To evaluate the macroporosity, mercury porosimetry technique (Micromeritics autopore IV) was performed applying the following conditions: increasing pressure up to $228 \mathrm{MPa}$, surface tension value of $0.485 \mathrm{~N} / \mathrm{m}$ and a contact angle of $130^{\circ}$. The average pore size $\left(D_{p}\right)$ was estimated by the Washburn's intrusion theory.

To examine the morphology of the samples, high-resolution transmission electron microscopy (HRTEM) was employed using a JEOL JEM-2100F microscope operated at an accelerating voltage of $200 \mathrm{kV}$ and equipped with a field emission gun (FEG) and an ultra-high resolution pole-piece that provided a point-resolution better than $0.19 \mathrm{~nm}$. Prior 
to the examination, the samples were dispersed in ethanol, sonicated, sprayed on a carboncoated copper grid and finally air-dried. Additionally, the morphology of the samples was also examined by using a Quanta FEG 650 scanning electron microscope (SEM) with an accelerating voltage of $25 \mathrm{kV}$ and a secondary electron detector EDT (EverhartThornley). This device is equipped with an Apollo X detector for EDX measurements. For these analyses, samples were previously attached to an aluminium sample holder using conductive double-sided adhesive tape.

X-ray diffraction (XRD) experiments were carried out on a Bruker D8 Advance powder diffractometer fitted with an internal standard of silicon powder and a monochromatic $\mathrm{Cu}-\mathrm{K} \alpha \mathrm{X}$-ray source with $0.1542 \mathrm{~nm}$ of wavelength. The results were compiled over a $2 \theta$ range from $5^{\circ}$ to $80^{\circ}$ with a step size of $0.02^{\circ}$ and an exposure of $3 \mathrm{~s}$ per step.

The X-ray photoelectron spectroscopy (XPS) was performed in an SPCS Phoibos 100 apparatus using $\mathrm{Mg}$-K $\alpha \mathrm{X}$-rays $(1254.6 \mathrm{eV})$ programmed to operate at a power of $100 \mathrm{~W}$ and with a residual vacuum of $10^{-7} \mathrm{~Pa}$. An analyzer with $50 \mathrm{eV}$ pass energy was used to collect the broad scan spectra $(0-1100 \mathrm{eV})$. The atomic percentages (at.\%) of the different elements present in the approximately $10 \mathrm{~nm}$ upper layer were calculated from the survey spectra by integrating the areas of the main peaks.

The electrical conductivity was evaluated by the four-point probe (FPP) method applied to disc-shaped pellets made of the studied carbon xerogels. The disc-shaped pellets were prepared by mixing $90 \mathrm{wt} . \%$ of each material with $10 \mathrm{wt} . \%$ of polytetrafluoroethylene (PTFE) as a binder, a detailed description of their assembly is available in the literature [33]. FPP technique was performed by placing the four points in contact with the surface of disc-shaped pellets and applying a constant current in the range of 9-10 mA between the four points (DC source model 6220, Keithley). The corresponding voltage drop was measured using a digital nanovoltmeter (model 2182 A, Keithley). 


\subsection{Electrode and cell preparation}

To perform the electrochemical analysis a three-electrode testing cell coupled to a PGSTAT 302N potentiostat/galvanostat from AUTOLAB was employed. The configuration involves a $150 \mathrm{~mL}$ capacity beaker-type cell with three electrodes (reference, counter and working) immersed in an electrolyte solution $(\mathrm{KOH} \mathrm{0.1} \mathrm{M).} \mathrm{The}$ electrodes selected were: (i) an electrode of $\mathrm{Ag} / \mathrm{AgCl}$ (3 M) as reference electrode, (ii) a glassy carbon rod as the counter electrode and (iii) a glassy carbon rotating disk electrode (RDE Metrohm $3 \mathrm{~mm}$ of diameter) or a glassy carbon rotating ring-disk electrode (RRDE Metrohm $5 \mathrm{~mm}$ of diameter) as the working electrode. An ink of the electrocatalyst was deposited on the working electrode. The ink was prepared by dispersing $1 \mathrm{mg}$ of milled sample in $220 \mu \mathrm{L}$ of ultrapure water, $142 \mathrm{~mL}$ of EtOH and $96 \mu \mathrm{L}$ of Nafion $(5$ wt.\% in water, Sigma-Aldrich). The mixture was ultrasonicated for $30 \mathrm{~min}$ until its homogenization and then deposited on the working electrode with a mass loading of ca $0.1 \mathrm{mg} / \mathrm{cm}^{2}$. After its deposition, the ink was dried at room temperature.

\subsection{Electrochemical characterization}

Cyclic voltammetry (CV) and linear sweep voltammetry (LSV) were performed at room temperature in a $0.1 \mathrm{M} \mathrm{KOH}$ electrolyte solution. Previously to each experiment, the electrolyte was saturated with the gas required $\left(\mathrm{O}_{2}\right.$ or $\left.\mathrm{N}_{2}\right)$ for $30 \mathrm{~min}$. The cyclic voltammetry was performed from 0 to $1.2 \mathrm{~V}$ vs RHE with a swept rate of $5 \mathrm{mV} / \mathrm{s}$. Linear swept voltammetry (LSV) using the rotating disk electrode (RDE) was carried out in the range of $0-1.2 \mathrm{~V}$ vs RHE at a scan rate of $5 \mathrm{mV} / \mathrm{s}$ under a disk rotation rate from 400 to 
$3000 \mathrm{rpm}$. The apparent number of electrons transferred for ORR was calculated applying the Koutecky-Levich equation:

$$
\begin{aligned}
& \frac{1}{J}=\frac{1}{J_{L}}+\frac{1}{J_{k}}=\frac{1}{B w^{1 / 2}}+\frac{1}{J_{k}} \\
& B=0.2 n F C_{0}\left(D_{0}\right)^{\frac{2}{3}} v^{-\frac{1}{6}}
\end{aligned}
$$

Where $\mathrm{J}$ is the measured current density, $\mathrm{J}_{\mathrm{K}}$ is the kinetic current density, $\mathrm{J}_{\mathrm{L}}$ is the diffusion-limited current density, $\mathrm{w}$ is the electrode rotation rate (rpm), F is the Faraday constant $(96485 \mathrm{C} / \mathrm{mol}), \mathrm{C}_{0}$ is the bulk concentration of $\mathrm{O}_{2}\left(1.15 \times 10^{-3} \mathrm{~mol} / \mathrm{cm}^{3}\right), \mathrm{D}_{0}$ is the diffusion coefficient of $\mathrm{O}_{2}\left(1.95 \times 10^{-5} \mathrm{~cm}^{2} / \mathrm{s}\right)$ and $\mathrm{v}$ is the kinematic viscosity of the electrolyte $\left(0.009 \mathrm{~cm}^{2} / \mathrm{s}\right)$

The onset potential $\left(\mathrm{E}_{\text {onset }}\right)$ was estimated as the potential at a current density of -0.1 $\mathrm{mA} / \mathrm{cm}^{2}$. All the measured potentials vs the reference electrodes, i.e. $\mathrm{Ag} / \mathrm{AgCl}(3 \mathrm{M})$, were converted to the reversible hydrogen electrode (RHE) from the following equation:

$$
E_{R H E}=0.059 p H+E_{A g / A g C l}^{0}+E_{A g / A g C l}
$$

Where $\mathrm{E}_{\mathrm{Ag} / \mathrm{AgCl}}$ is the measured potential vs $\mathrm{Ag} / \mathrm{AgCl}(3 \mathrm{M})$ and $\mathrm{E}^{0}{ }_{\mathrm{Ag} / \mathrm{AgCl}}=0.21 \mathrm{~V}$ at 20 ${ }^{\circ} \mathrm{C}[19]$.

The tests carried out using the ring-disk electrode (RRDE) as the working electrode were performed at the same working conditions as those with the RDE. The percentage of $\mathrm{H}_{2} \mathrm{O}_{2}$ produced during the ORR and the number of electrons transferred using this working electrode were calculated by the following equations:

$$
n=\frac{4 I_{D}}{I_{D}+\frac{I_{R}}{N}}
$$




$$
\% H_{2} O_{2}=100 \frac{2 I_{R} / N}{I_{D}+\frac{I_{R}}{N}}
$$

Where $I_{D}$ is the Faradaic current at the disk, $I_{R}$ is the Faradaic current at the ring, $N$ is the $\mathrm{H}_{2} \mathrm{O}_{2}$ collection coefficient at the ring $(\mathrm{N}=0.249)$. The derivation of equation 4 and 5 is provided in the Supporting Information.

\section{Results and discussion}

\subsection{Effect of the thermal treatment}

Results of the nitrogen physisorption and mercury porosimetry analyses of the carbon xerogels are shown in Figure 1. It was observed that carbon xerogels develop different porosities depending on the heat treatment used. Samples CX-750 and AX-1000 show isotherms that are a combination of type I and II in accordance with the IUPAC classification (Figure 1a). The volume of nitrogen adsorbed increases quickly at low relative pressures, which is characteristic of microporous materials. The isotherm of sample AX-1000 reaches the highest volume of gas adsorbed (y-axis) at low relative pressures, indicating a larger volume of micropores $\left(\mathrm{S}_{\mathrm{BET}}=1460 \mathrm{~m}^{2} / \mathrm{g}\right.$ and $\mathrm{V}_{\mathrm{DR}}=0.5$ $\left.\mathrm{cm}^{3} / \mathrm{g}\right)$ than sample CX-750 $\left(\mathrm{S}_{\mathrm{BET}}=644 \mathrm{~m}^{2} / \mathrm{g}\right.$ and $\left.\mathrm{V}_{\mathrm{DR}}=0.2 \mathrm{~cm}^{3} / \mathrm{g}\right)$. Graphitization at $2000{ }^{\circ} \mathrm{C}$ (sample GX-2000) leads to a type II isotherm (Figure 1a) that is associated to macroporous materials with a low volume of micropores $\left(S_{\mathrm{BET}}=77 \mathrm{~m}^{2} / \mathrm{g}, \mathrm{V}_{\mathrm{DR}}=0.03\right.$ $\mathrm{cm}^{3} / \mathrm{g}$ ). Carbonization and activation processes give rise to carbon xerogels with a more developed microporosity since volatile compounds are released during the heat treatment, creating micropores inside the nodules that make up the polymer structure of the gels [30]. However, treatments at a higher temperature (i.e. the graphitization process) produce an ordering of the carbonaceous structure, which results in the minimization of 
the defects inside the polymeric nodules of the gel [32], and hence, in a sample with lower microporosity (GX-2000). Conversely, the isotherm of all three samples exhibits the same shape at relative pressures higher than 0.95 . The rise in the volume of nitrogen adsorbed at high pressure reveals the presence of macropores in their structures, which suggests that the different treatments performed do not alter the size of the nodules or the space between nodules and, in turn, samples with similar pore size distribution are obtained (i.e. Dp of ca. $85 \mathrm{~nm})$, as shown in Figure $1 \mathrm{~b}$.
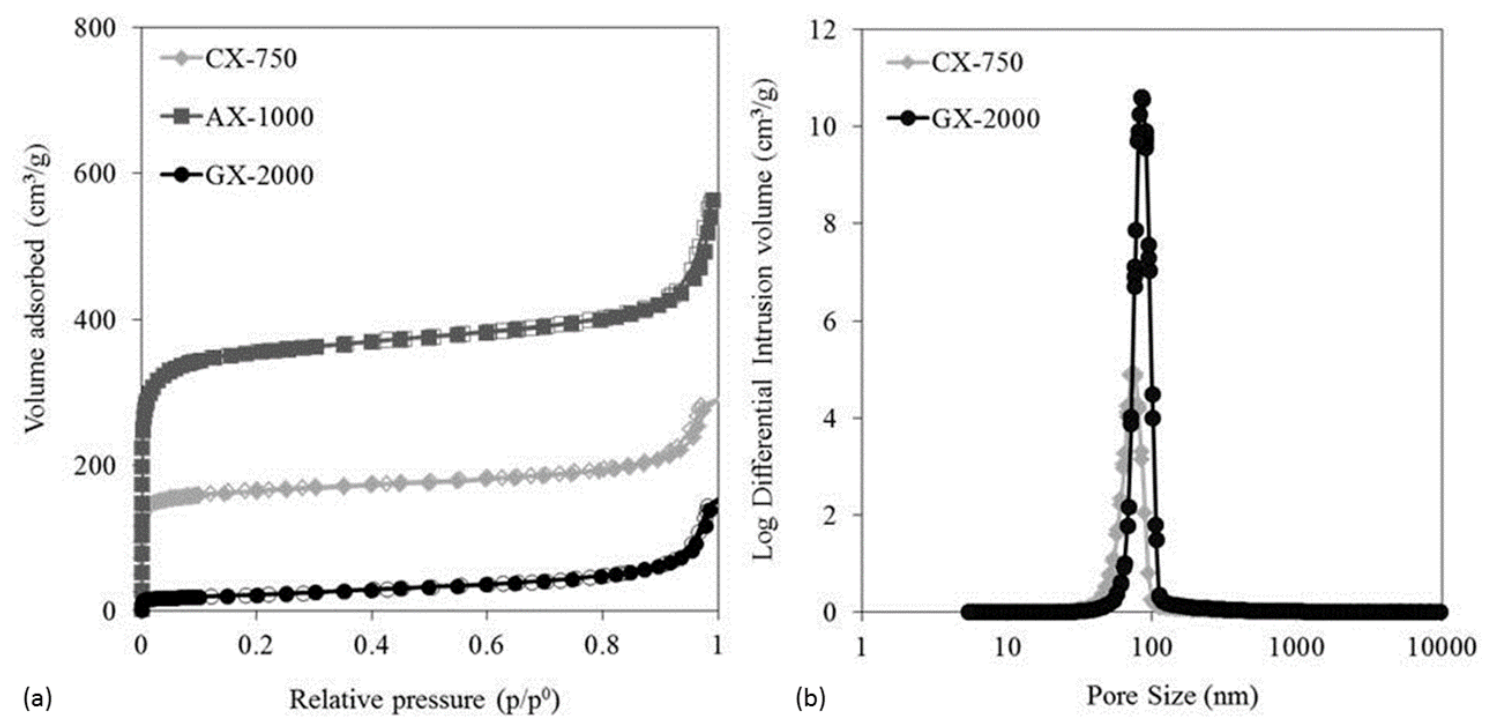

Figure 1. $\mathrm{N}_{2}$ adsorption-desorption isotherms (a) and pore size distributions obtained using mercury porosimetry (b) of the xerogels studied.

HRTEM images show that samples CX-750 and AX-1000 (Figure 2a and b) are formed by disordered carbonaceous sheets interconnected with each other, while in the structure of sample GX-2000 (Figure 2c), areas showing twisted graphene ribbons are also appreciated. Despite the relatively low temperature of the graphitization treatment $\left(2000{ }^{\circ} \mathrm{C}\right)$, some low-range graphene stacking is already observed in those nanostructures. 

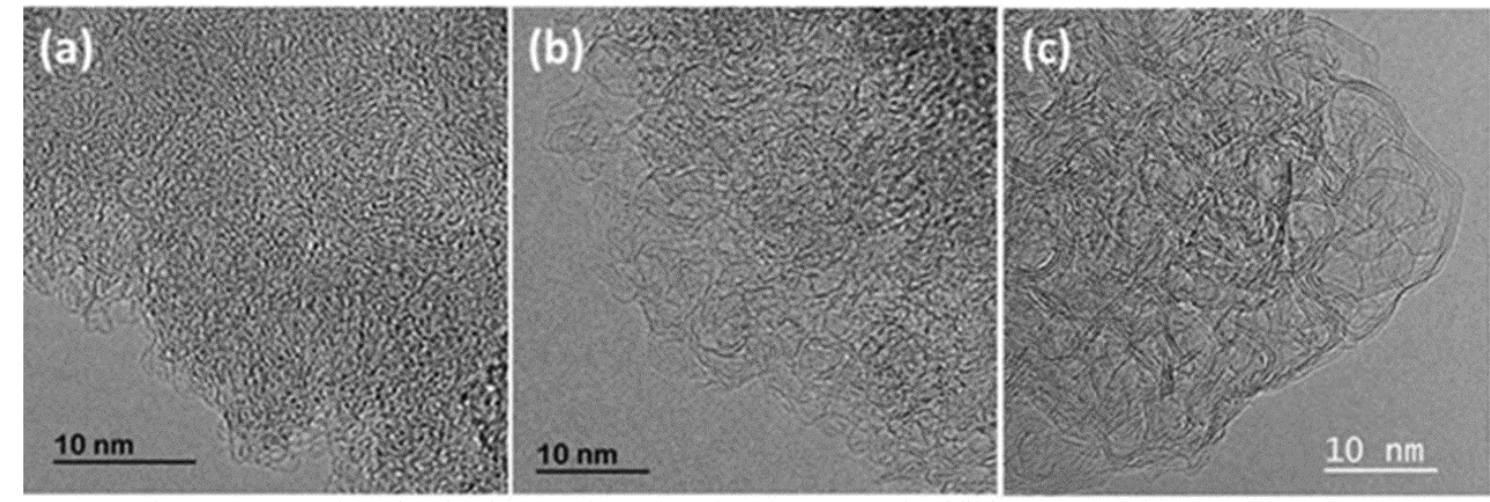

Figure 2. HRTEM images of CX-750 (a), AX-1000 (b) and GX-2000 (c).

Nevertheless, sample GX-2000 is far from being a graphitic material, as its XRD pattern (Figure $\mathrm{S} 1$ ) shows a wide band at around $2 \theta=25^{\circ}$ assigned to the (002) diffraction peak, which intensity is very low compared to that of graphite. Moreover, graphitic materials also show peaks at $2 \theta=43^{\circ}$ and $44^{\circ}$ corresponding to the (100) and (101) reflections [32], while only a broad band at ca. $43^{\circ}$ is observed in the XRD pattern of the sample GX-2000, which is characteristic of amorphous carbons [32].

Differences in the electrical conductivity of the samples are also observed (Figure 3). The variations in the ability of the materials for electron transport can be assigned to the different degree of ordering of the structure, which seems to depend mainly on the heat treatment applied. The higher the temperature of the treatment, the better the electrical conductivity of the carbon xerogel. Thus, CX-750 has an electrical conductivity of only $50 \mathrm{~S} / \mathrm{m}$ that is $61 \%$ and $86 \%$ lower than that of $\mathrm{AX}-1000$ and GX-2000, respectively. AX1000 is the sample with the highest volume of micropores that implies discontinuities that would prevent the passage of electrons. However, unlike at $750{ }^{\circ} \mathrm{C}$, at $1000{ }^{\circ} \mathrm{C}$ the carbonaceous structure seems to attain certain order that balances the micropores discontinuities. 


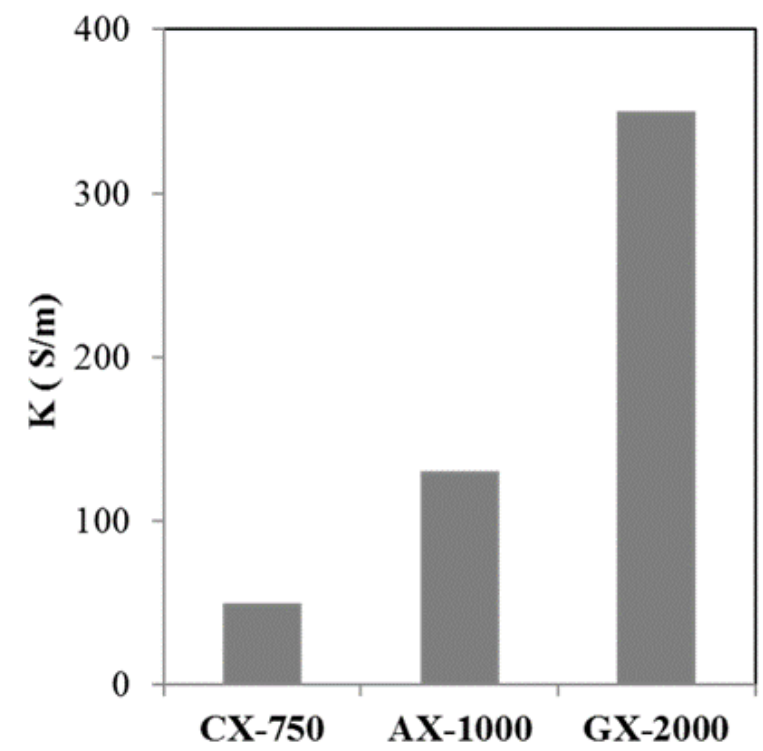

Figure 3. The electrical conductivity of the carbon xerogels studied.

The performance of the carbon xerogels as electrocatalysts for ORR was evaluated using cyclic voltammetry in a rotating disk electrode (RDE) (Figure 4). The cyclic voltammograms of all samples showed featureless profiles when the electrolyte was saturated with $\mathrm{N}_{2}$, whereas a well-defined cathodic peak is observed when the electrolyte was saturated with $\mathrm{O}_{2}$, evidencing the catalytic activity of the samples towards ORR. A well-defined peak appears at ca. 0.6 V for samples CX-750 and GX-2000 (Figure 4a and c), while in the case of sample AX-1000 the peak shifts to a higher potential $(0.7 \mathrm{~V}$, Figure 4b), suggesting a more significant electrocatalytic activity. 

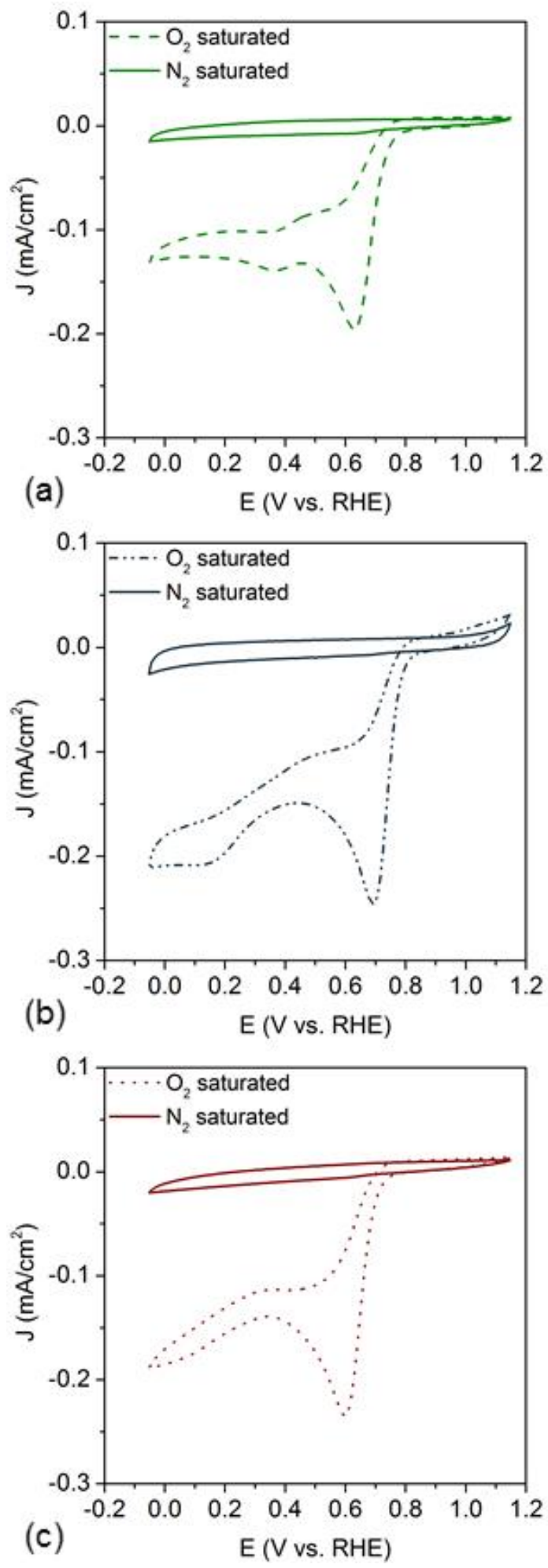

Figure 4. Cyclic voltammograms of CX-750 (a), AX-1000 (b) and GX-2000 (c) measured with a sweep rate of $5 \mathrm{mV} / \mathrm{s}$ in an electrolyte saturated with $\mathrm{N}_{2}$ and $\mathrm{O}_{2}$. 
The linear sweep voltammograms (LSV) recorded at $1600 \mathrm{rpm}$ are plotted in Figure 5a. Results from the LSV confirm the higher performance of sample AX-1000 as its onset potential $\left(\mathrm{E}_{\text {onset }}=0.754 \mathrm{~V}\right)$ is 57 and $86 \mathrm{mV}$ more positive than that of $\mathrm{CX}-750$ and GX2000, respectively. In addition, sample AX-1000 shows a larger value of limiting current density $\left(3.1 \mathrm{~mA} / \mathrm{cm}^{2}\right)$, which can be related to the combination of high electrical conductivity with the presence of pores of ca. $100 \mathrm{~nm}$ and a high volume of micropores. These factors allow the reactants to reach a larger amount of catalytic sites without diffusion limitations. Differences between the LSVs of sample CX-750 and GX-2000 are also observed. The E $E_{\text {onset }}$ of CX-750 (0.697 V) is $29 \mathrm{mV}$ higher than that of GX-2000. However, CX-750 registered the worst limiting current density $\left(1.7 \mathrm{~mA} / \mathrm{cm}^{2}\right)$, which is $35 \%$ lower in comparison with that of the xerogel treated at $2000{ }^{\circ} \mathrm{C}$. These differences in their electrochemical performance are due to their different physicochemical properties. CX-750 has a larger volume of micropores than GX-2000, which results in a higher value of $E_{\text {onset. }}$ However in the case of sample GX-2000 the lack of micropores is compensated by its high electrical conductivity, reaching a larger limiting current density. 

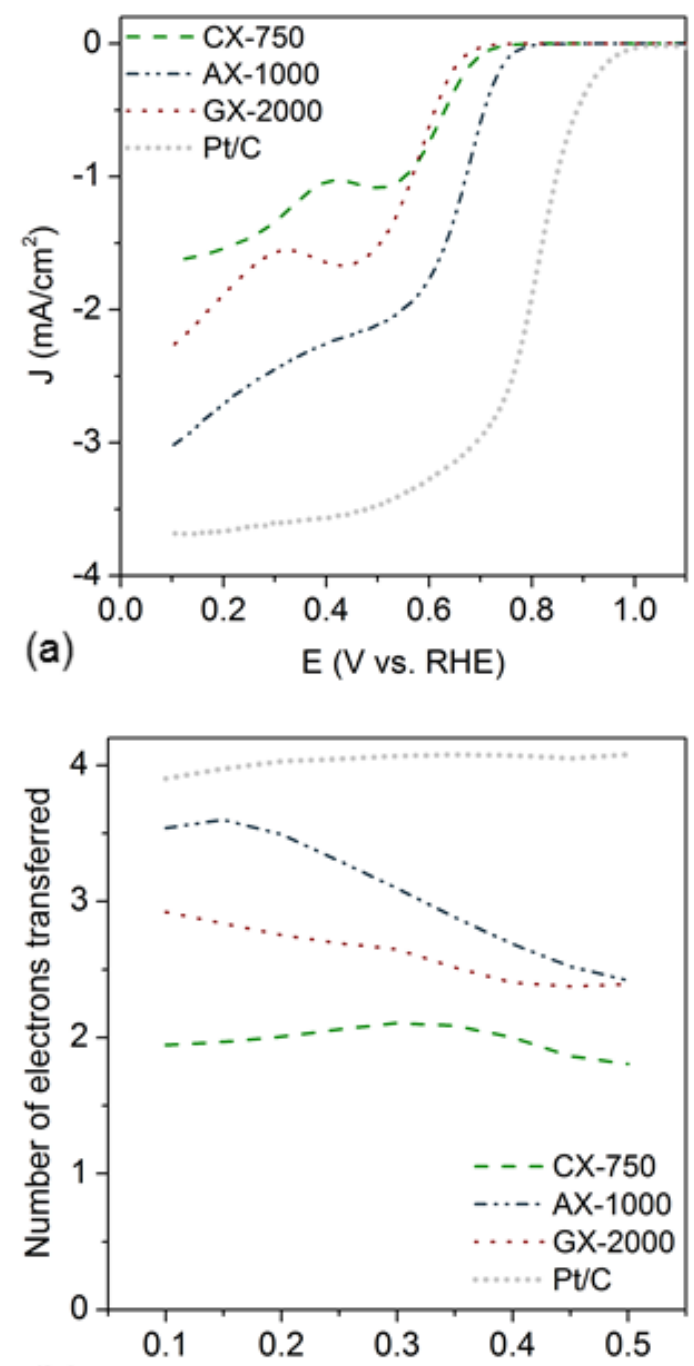

(b)

E (V vs. RHE)

Figure 5. Linear sweep voltammograms (LSV) at $1600 \mathrm{rpm}$ (a) and number of electrons transferred (b) during the ORR using xerogels as electrocatalysts.

The variation of the number of electrons is plotted in Figure 5b. Sample CX-750 clearly follows the 2-electron mechanism, suggesting the formation of byproducts such as hydrogen peroxide along all the potential range studied. The number of electrons transferred is higher for the activated and graphitized samples, although the value is not stable for the whole range of potential. At $0.15 \mathrm{~V}$, sample AX-1000 exhibits a number of electrons transferred of 3.6, which decreases at higher potentials, reaching the same 
number of electrons transferred as sample GX-2000 at $0.5 \mathrm{~V}(\mathrm{n}=2.4)$. These results suggest that microporosity and electrical conductivity of carbon xerogels clearly make a difference in their performance as electrocatalysts for ORR, being the combination of both properties essential to improve their electroactivity. However, the performance of these carbon xerogels is still far from that of the reference material $\mathrm{Pt} / \mathrm{C}$, also tested under the same operating conditions (see Figure 5), suggesting that the physicochemical properties of the carbon xerogels should be further modified. According to literature, the presence of certain nitrogen groups linked to the carbon structure enhances the catalytic activity [22]. In particular, quaternary and pyridinic nitrogen groups have been proposed as ORR active sites [17, 19]. Consequently, carbon xerogels were functionalized to evaluate the effect of the nitrogen functional groups on their electrochemical performance.

\subsection{Effect of nitrogen functionalization}

Carbonized, activated and graphitized carbon xerogels were impregnated with melamine and heated up to $700{ }^{\circ} \mathrm{C}$ in order to attach nitrogen groups to their carbonaceous framework. Melamine decomposes at temperatures above $400{ }^{\circ} \mathrm{C}$ starting with the loss of its amino groups that may react with the carbon structure, giving rise to surface nitrogen groups. The surface elemental composition and the nature of the functional groups of the resulting nitrogen-doped samples were analyzed by XPS. The atomic percentage obtained from their corresponding survey spectra (Figure S2) are presented in Table 1. Carbon and oxygen are present in all samples, while nitrogen was only observed for CX-750N and AX-1000N. The percentage of carbon in the samples increases with the temperature of the thermal treatment applied, whereas the amount of oxygen and nitrogen decreases. As the carbon structure of sample CX-750 is more reactive, due to its more disordered 
structure and the presence of oxygen surface functionalities, a higher amount of nitrogen surface groups are incorporated, i.e. a larger amount of nitrogen (Table 1). Conversely, sample $\mathrm{AX}-1000$ has a more ordered structure in comparison to $\mathrm{CX}-750$, which results in the incorporation of a lower amount of nitrogen (Table 1). From the results in Table 1, it should also be noted that the addition of melamine and subsequent thermal treatment does not seem to produce the incorporation of nitrogen functionalities in sample GX-2000N. This phenomenon could be attributed to the fact that this sample presents a highly ordered structure, composed by condensed carbon molecules with nearly no surface groups and low content of defects, as inferred from the low $\mathrm{N}_{2}$ adsorption shown in Figure 1, leading to a low concentration of active sites for the incorporation of heteroatoms during the functionalization treatment.

Table 1. Atomic percentages obtained from XPS analysis for samples treated with melamine.

\begin{tabular}{|c|c|c|c|}
\hline At. $\%$ & CX-750N & AX-1000N & GX-2000N \\
\hline C & 87.2 & 92.8 & 96.7 \\
\hline O & 10.4 & 5.4 & 3.3 \\
\hline N & 2.4 & 1.8 & - \\
\hline
\end{tabular}

Interestingly, different types of nitrogen functionalities were found on the carbonized and activated samples. The XPS spectrum of the N1s region of sample CX-750N (Figure 6a) was deconvoluted in two asymmetric peaks attributed to pyridinic $(398.4 \pm 0.1 \mathrm{eV})$ and pyrrolic $(400.2 \pm 0.2 \mathrm{eV})$ structures, while a third peak ascribed to quaternary nitrogen $(401.7 \pm 0.2 \mathrm{eV})$ was also observed for sample AX-1000N (Figure 6b) $[14,17,22]$. From the previous discussion, it is clear that although sample $\mathrm{AX}-1000$ has a relatively more ordered structure than CX-750 is still reactive towards nitrogen functionalization (Table 1). This could be due to the higher volume of micropores that may act as active sites, making melamine interacts with the carbon structure via a different mechanism than that 
taking place due to the chemical surface functionalities. As a result, different nitrogen functionalities, such as quaternary nitrogen, are incorporated in the activated carbon xerogel.
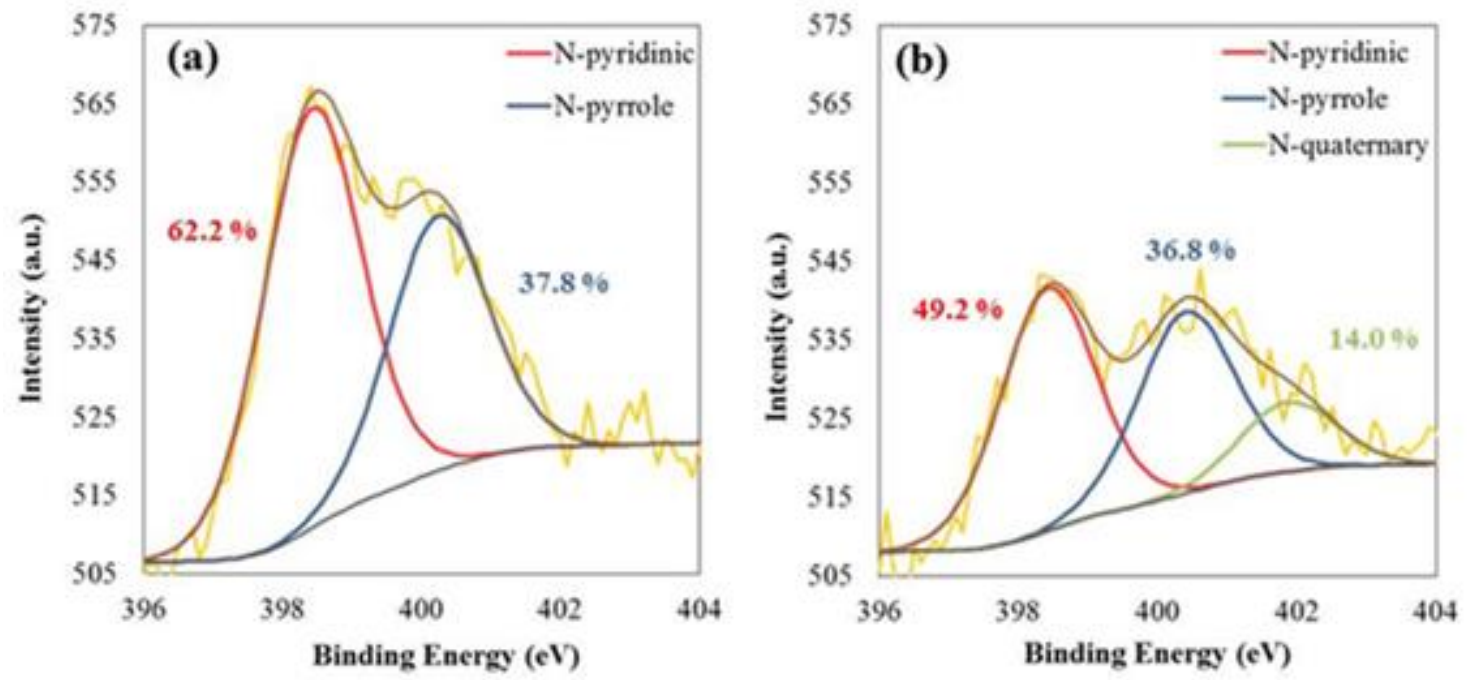

Figure 6. XPS spectra of N 1s region of sample CX-750N (a) and AX-1000N (b).

Cyclic voltammograms of the N-doped carbon xerogels (Figure 7) show again homogeneous profiles in the $\mathrm{N}_{2}$-saturated electrolyte. In the $\mathrm{O}_{2}$-saturated experiments, a remarkable cathodic peak appears at ca. 0.66 and $0.64 \mathrm{~V}$ for CX-750N (Figure 7a) and GX-2000N (Figure 7c), respectively. The sample AX-1000N shows the most intense peak at $0.70 \mathrm{~V}$ (Figure $7 \mathrm{~b}$ ), which evidences once again its superior behaviour towards ORR. 

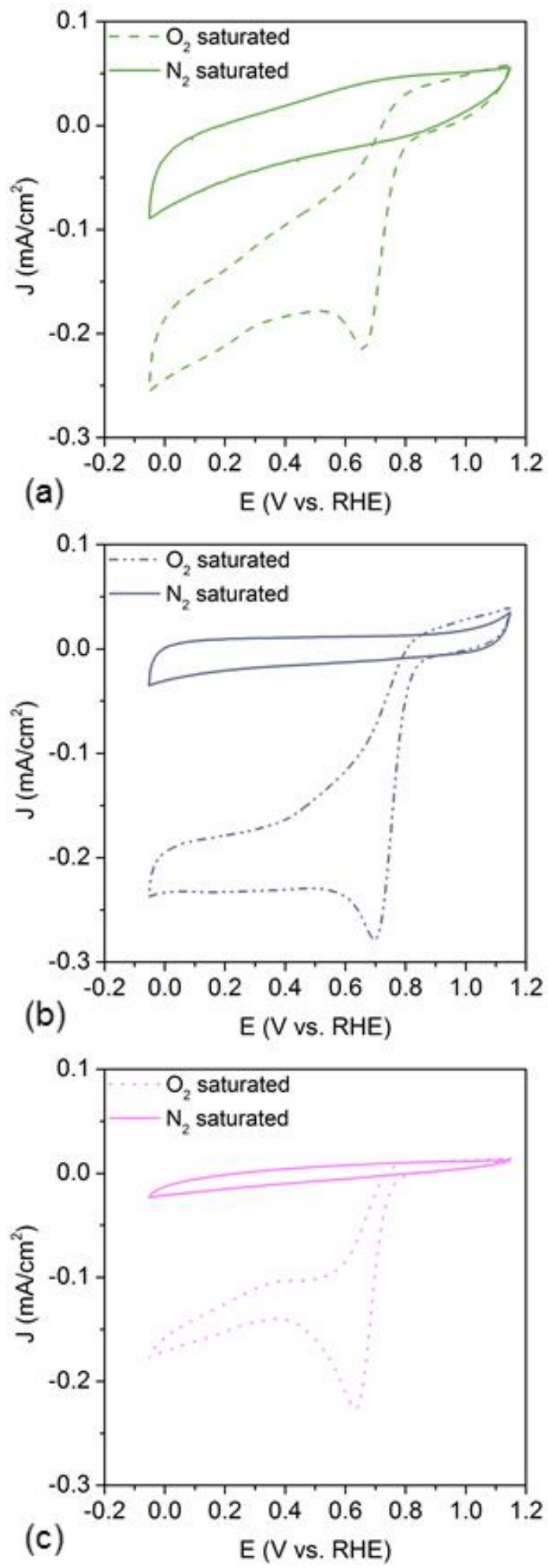

Figure 7. CV profiles of the N-doped samples CX-750N (a), AX-1000N (b) and GX$2000 \mathrm{~N}$ (c), measured with a sweep rate of $5 \mathrm{mV} / \mathrm{s}$ in an electrolyte saturated with $\mathrm{N}_{2}$ and $\mathrm{O}_{2}$. 
The LSVs recorded at $1600 \mathrm{rpm}$, the number of electrons transferred and the percentage of $\mathrm{H}_{2} \mathrm{O}_{2}$ produced during the ORR are shown in Figure $8 \mathrm{a}, 8 \mathrm{~b}$, and $8 \mathrm{c}$, respectively. The performance of samples $\mathrm{CX}-750 \mathrm{~N}$ and $\mathrm{AX}-1000 \mathrm{~N}$ is clearly improved with respect to their corresponding undoped precursors (CX-750 and AX-1000). The onset potential and the limiting current density of sample CX-750N undergo an enhancement of a $6 \%$ and $60 \%$, respectively, probably due to the presence of the nitrogen functionalities. In addition, CX-750N performance surpasses that of GX-2000N, which can be attributed to the catalytic activity of the nitrogen functionalities that compensates the relatively low electrical conductivity of sample CX-750 (Figure 3). Besides, the selectivity of sample CX-750N towards the ORR was notably improved (Figure $8 \mathrm{~b}$ vs Figure 5b) and the number of electrons transferred is quite similar to that of GX-2000N. This effect is probably due to the high amount of pyridinic groups $(62.2 \%)$, which enhances the catalytic activity of carbons and improves the selectivity of the materials through the 4electron pathway. On the other hand, no nitrogen functionalities were incorporated into GX-2000N as a consequence of its low reactive structure, and hence, its catalytic activity is practically the same as that of the undoped counterpart (GX-2000). Although the addition of nitrogen into sample CX-750 has improved its electrochemical performance, the amount of $\mathrm{H}_{2} \mathrm{O}_{2}$ generated is around $60 \%$ in the whole range of potentials (Figure 8c). 

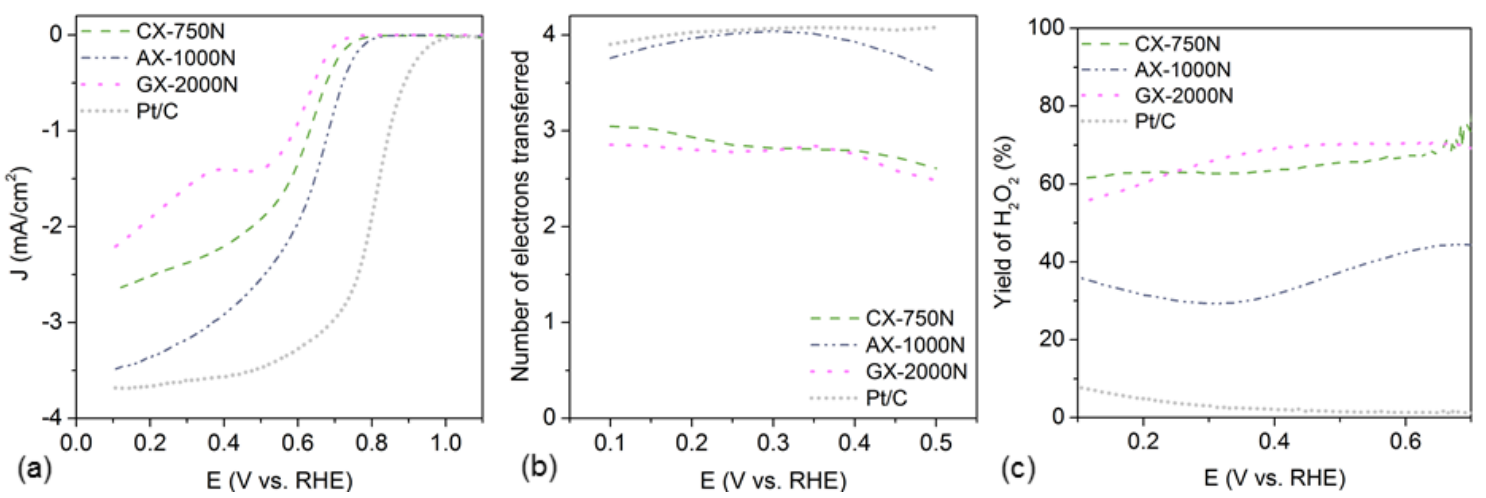

Figure 8. LSV at $1600 \mathrm{rpm}$ (a), number of electrons transferred (b) and percentage of hydrogen peroxide generated (c) for the $\mathrm{N}$-doped carbon xerogels.

$\mathrm{AX}-1000 \mathrm{~N}$ registered the highest $\mathrm{E}_{\text {onset }}(0.777 \mathrm{~V}), 23 \mathrm{mV}$ larger than that of $\mathrm{AX}-1000$, and the highest limiting current density value $\left(3.4 \mathrm{~mA} / \mathrm{cm}^{2}\right)$, which is quite similar to that of Pt/C measured under the same conditions $\left(3.6 \mathrm{~mA} / \mathrm{cm}^{2}\right)$. Sample AX-1000N exhibits higher electroactivity even tough has a nitrogen content $25 \%$ lower than CX-750N (Table 1). This could be due to the incorporation of quaternary nitrogen into the $A X-1000 \mathrm{~N}$ structure, which does not appear in CX-750N. Several authors claim that N-quaternary has a higher catalytic activity towards ORR $[19,24]$, which is in agreement with the results obtained in the present study. Besides, recent literature has shown that the most crucial parameters are the ratios between the nitrogen functionalities. It seems that a higher pyridinic-N/quaternary-N ratio favours the onset potential, while a lower quaternary-N/pyrrolic-N ratio favours the number of electrons exchanged [22, 23]. Based on this hypothesis, it can be assumed that the fact of having quaternary groups is not the main reason to improve the electrocatalytic activity of sample $\mathrm{AX}-1000 \mathrm{~N}$, but the ratio between pyridinic and quaternary nitrogen functionalities. In fact, the values of this ratio and the onset potential obtained for sample $\mathrm{AX}-1000 \mathrm{~N}$ are quite similar to those already published for other types of carbon materials [22]. Therefore, the best performance of $\mathrm{AX}-1000 \mathrm{~N}$ can be explained in terms of its content in pyridinic and quaternary nitrogen, 
a relatively high electrical conductivity and a well-developed porosity that combines micropores and macropores, that enable a good diffusion of the reactants. Furthermore, the behaviour of $\mathrm{AX}-1000 \mathrm{~N}$ is close to that of the 4-electron pathway, producing only $30 \%$ of $\mathrm{H}_{2} \mathrm{O}_{2}$ at $0.3 \mathrm{~V}$. Nevertheless, the mechanism of the reaction does not remain stable at all potentials studied (Figure 8b). For this sample, the number of electrons decreased to 3.6 at $0.5 \mathrm{~V}$ with a production of $40 \%$ of $\mathrm{H}_{2} \mathrm{O}_{2}$. In addition and despite the improvements obtained due to the incorporation of nitrogen functionalities, the $\mathrm{E}_{\mathrm{onset}}$ of AX-1000N is still far from that of the Pt-based commercial material (Figure 8). To overcome this drawback, iron particles were incorporated into sample AX-1000N.

\subsection{Effect of the combination of nitrogen and iron}

Iron was incorporated into the structure of the sample AX-1000N by incipient wetness impregnation of FePc (sample AX-1000NFe). The chemical composition of the sample AX-1000NFe differs slightly from AX-1000N. In addition to the presence of iron (0.2 at. $\%)$, the percentage of nitrogen in $\mathrm{AX}-1000 \mathrm{NFe}$ is higher than in $\mathrm{AX}-1000 \mathrm{~N}$ (2.3 a. $\mathrm{t} \%$ vs. 1.8 at. \%, respectively) due to the phthalocyanine moiety. The deconvolution of the $\mathrm{C} 1 \mathrm{~s}$ and O1s XPS regions is similar to that obtained for its AX-1000N counterpart (Figure S3 and S4). However, differences in the contribution of the nitrogen functionalities are observed (Figure 9). The contribution of pyridinic nitrogen increased by $32.2 \%$, which can be attributed to the fact that FePc is composed mainly by $\mathrm{N}$-pyridinic groups and to a lower extent by N-pyrrolic groups [13], and hence, the percentage of quaternary functionalities is lower in sample AX-1000NFe than in sample AX-1000N. The amount of iron detected using XPS is quite low (ca. 0.2 at. \% of Fe), but EDX mapping analysis shows that the metal is incorporated and homogeneously distributed across the carbonaceous structure of the xerogel (Figure 10). 


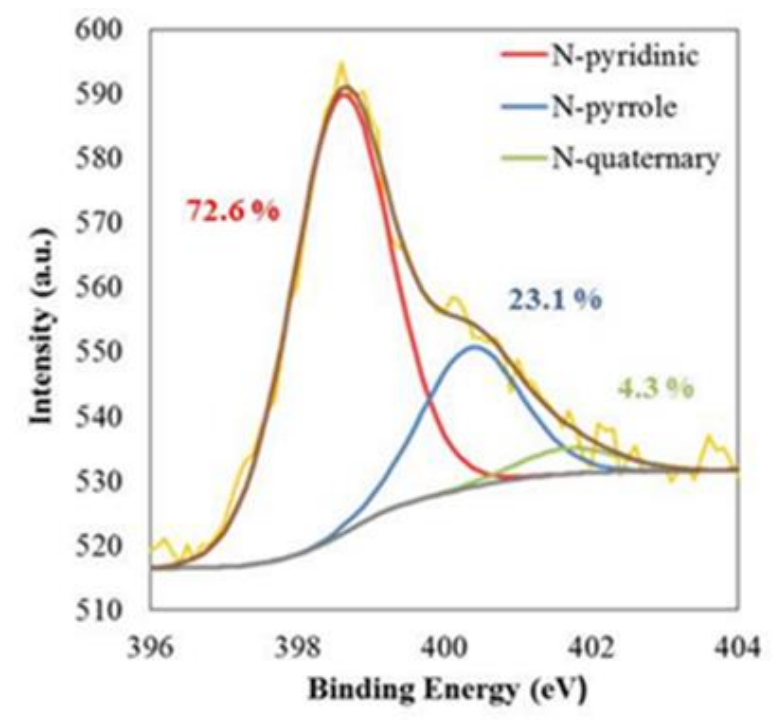

Figure 9. XPS N1s spectra of AX-1000NFe.
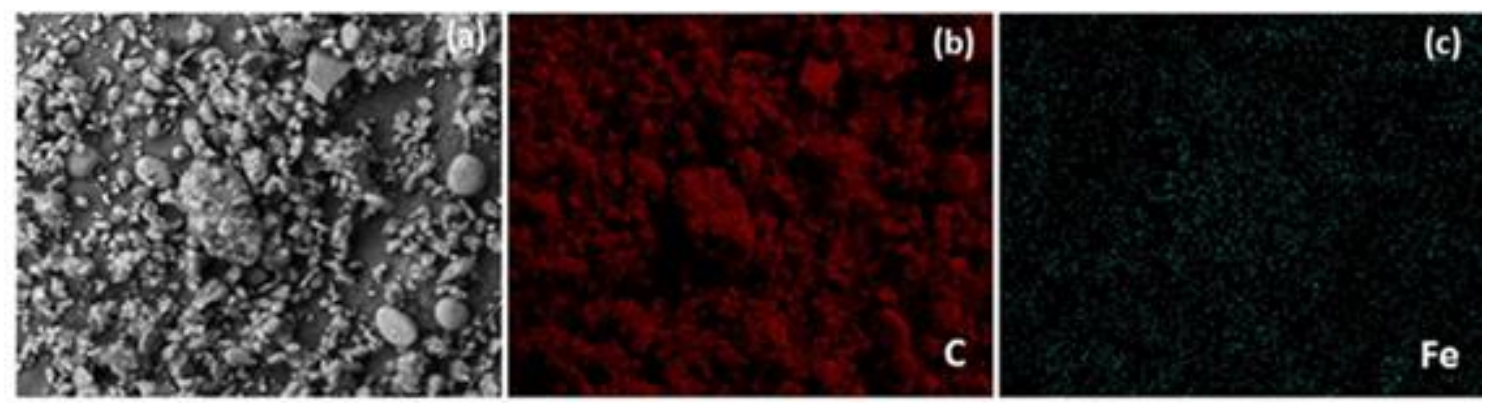

Figure 10. SEM image of $\mathrm{AX}-1000 \mathrm{NFe}$ (a) and its corresponding mapping of carbon (b) and iron (c).

The electrocatalytic activity of sample AX-100NFe towards ORR was also evaluated and the results obtained are shown in Figure 11. The results of the CVs plotted in Figure 11a show that AX-1000NFe has a high electrocatalytic activity, as inferred by the pronounced cathodic peak that appears $23 \%$ shifted toward higher values than that of $\mathrm{AX}-1000 \mathrm{~N}$ when the electrolyte was saturated with oxygen. Moreover, that peak is clearly more intense than that of AX-1000N, reaching a current density of $0.40 \mathrm{~mA} / \mathrm{cm}^{2}$, which implies a $30 \%$ enhancement. These results suggest that the presence of a small amount of iron on the carbon material plays an important role. 

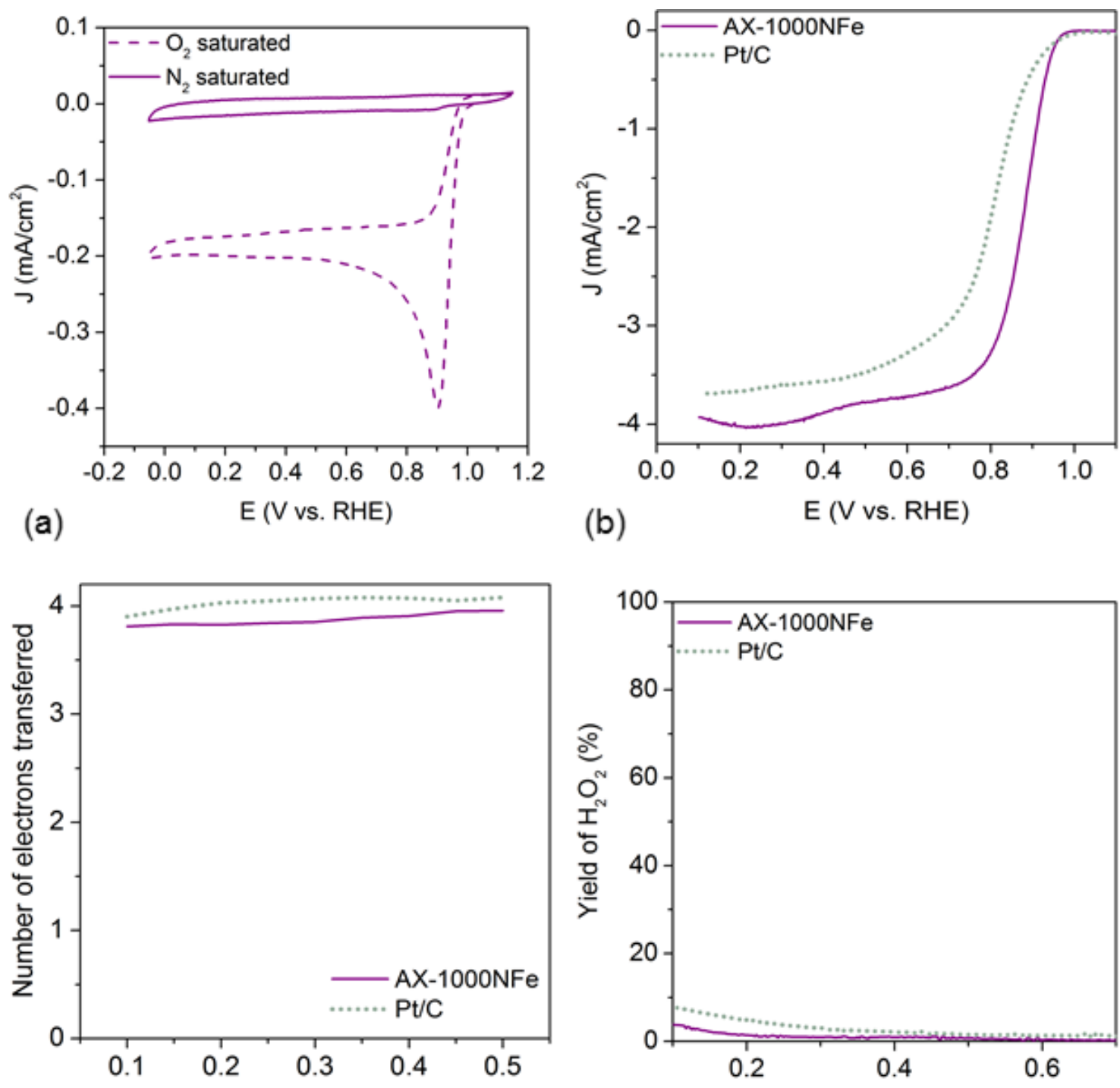

(c) E (V vs. RHE)

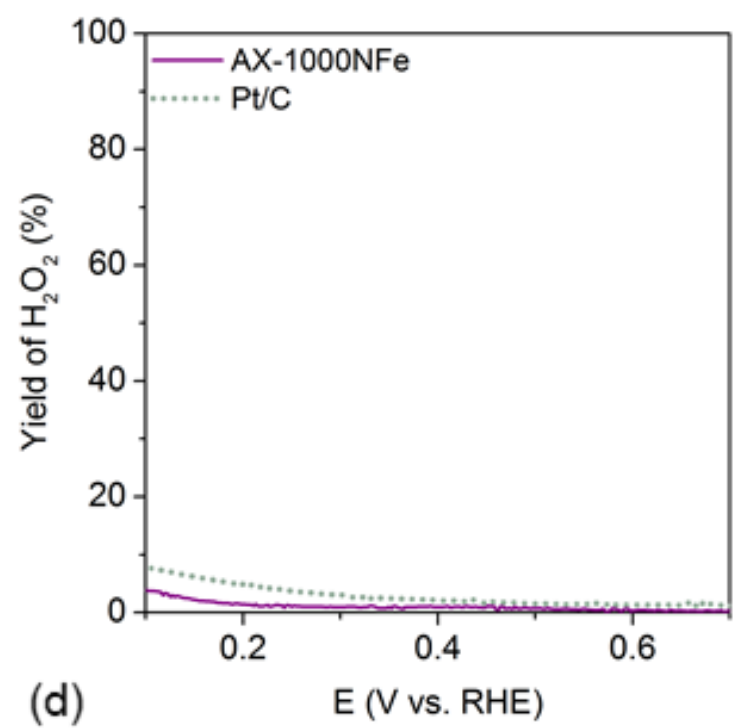

Figure 11. CV measured with a sweep rate of $5 \mathrm{mV} / \mathrm{s}$ in an electrolyte saturated with $\mathrm{N}_{2}$ and $\mathrm{O}_{2}$ (a), LSV at $1600 \mathrm{rpm}$ (b), number of electrons transferred (c) and production of hydrogen peroxide (c) for AX-1000NFe and the reference material Pt/C.

The linear sweep voltammogram recorded at $1600 \mathrm{rpm}$ (Figure 11b) corroborates the cyclic voltammetry results. AX-1000NFe surpasses the performance of the commercial $\mathrm{Pt} / \mathrm{C}$ concerning the limiting current density value and exhibits an identical onset potential $\left(0.960 \mathrm{~V}\right.$ measured at $\left.-0.1 \mathrm{~mA} / \mathrm{cm}^{2}\right)$ and similar stability (current decay lower than $20 \%$ after $15000 \mathrm{~s}$, Figure SX). This value is $182 \mathrm{mV}$ higher than that of $\mathrm{AX}-1000 \mathrm{~N}$, which is 
attributed to its higher content of nitrogen, the higher ratio between pyridinic and quaternary nitrogen, and the iron coordinated with those nitrogen groups [15]. Furthermore, the addition of iron contributes also to improve the electrocatalytic selectivity towards an efficient four-electron mechanism (Figure 11c). The amount of $\mathrm{H}_{2} \mathrm{O}_{2}$ produced is almost negligible for all range of potentials studied (Figure 11d), which confirms the high selectivity of this electrocatalyst and that the ORR takes place predominantly via the 4-electron pathway. As mentioned above, this mechanism is probably favour by the low ratio between quaternary and pyrrolic groups and the presence of iron nanoparticles. These results suggest that $\mathrm{AX}-1000 \mathrm{NFe}$ is a promising electrocatalyst for ORR as i) the percentage of iron (II) phthalocyanine used in the present study is quite low and ii) the carbon xerogels used as supports are synthesized via microwave heating which is an easy, affordable and scalable process.

\section{Conclusions}

Carbon xerogels with different micropore volumes and electrical conductivities were prepared by applying different heat treatments to a macroporous organic xerogel synthesized by microwave heating. Micropores house most of the active sites that enhance the ORR, while the presence of macropores and a high electrical conductivity decrease the diffusion limitations. However, although differences in the catalytic activity of carbon xerogels are observed as a function of their porous structure, their performance still remains far from that of $\mathrm{Pt} / \mathrm{C}$. Nevertheless, the incorporation of nitrogen functionalities improves the catalytic activity of carbon xerogels towards ORR, especially if part of the nitrogen is incorporated as quaternary nitrogen, giving rise to the appropriate proportion between nitrogen groups: high pyrrolic/quaternary ratio and low quaternary/pyrrolic ratio. The presence of microporosity enables the incorporation of these quaternary groups into the carbon xerogel structure, suggesting that the porous 
structure not only plays a role in the diffusion of reactants during ORR and in the electrical conductivity of the samples but also influences on the type of nitrogen functionalities incorporated during post-synthesis treatments. Accordingly, the appropriate combination of these factors is mandatory to improve the performance in ORR. Despite the improvements obtained with the incorporation of nitrogen, the production of oxygen peroxide during the ORR was still observed. This drawback was completely reduced by the combination of the appropriate nitrogen functionalities with iron, which resulted in a material with enhanced electrocatalytic activity and an efficient selectivity towards ORR that took place preferentially via the four-electron mechanism. In fact, the activated carbon xerogel doped with $\mathrm{N} / \mathrm{Fe}$ showed a performance close to that of the reference material $(\mathrm{Pt} / \mathrm{C})$, opening the possibility towards the production of affordable electrocatalysts.

\section{Acknowledgment}

The authors gratefully acknowledge the financial support received from the Ministerio de Economía, Industria y Competitividad from Spain (Project CTQ2017-87820-R) and Principado de Asturias-FICYT-FEDER (Project PCTI-Asturias IDI/2018/000118). MCR also acknowledges the support from CSIC (Project I.E. 201880E010). This work was also partially supported by the projects "UniRCell", with the reference POCI-01-0145FEDER-016422, Project POCI-01-0145-FEDER-006984 - Associate Laboratory LSRELCM funded by ERDF through COMPETE2020 - Programa Operacional Competitividade e Internacionalização (POCI) - and by national funds through FCT Fundação para a Ciência e a Tecnologia.

\section{References}


[1] Z. Wu, M. Song, J. Wang, X. Liu, Recent Progress in Nitrogen-Doped Metal-Free Electrocatalysts for Oxygen Reduction Reaction, Catalysts, 8 (2018) 196.

[2] Y. Wang, B. Fang, X. Wang, A. Ignaszak, Y. Liu, A. Li, L. Zhang, J. Zhang, Recent advancements in the development of bifunctional electrocatalysts for oxygen electrodes in unitized regenerative fuel cells (URFCs), Prog. Mater. Sci., 98 (2018) 108-167.

[3] C. Wang, F. Yang, C. Xu, Y. Cao, H. Zhong, Y. Li, Sulfur-doped porous graphene frameworks as an efficient metal-free electrocatalyst for oxygen reduction reaction, Mater. Lett., 214 (2018) 209-212.

[4] J. Stacy, Y.N. Regmi, B. Leonard, M. Fan, The recent progress and future of oxygen reduction reaction catalysis: A review, Renew. Sust. Energ. Rev., 69 (2017) 401-414.

[5] M. Hunsom, D. Kaewsai, A.M. Kannan, Recent developments in bifunctional air electrodes for unitized regenerative proton exchange membrane fuel cells - A review, Int. J. Hydrogen Energy, (2018) 21478-21501.

[6] G.A. Ferrero, N. Diez, M. Sevilla, A.B. Fuertes, Iron/Nitrogen co-doped mesoporous carbon synthesized by an endo-templating approach as an efficient electrocatalyst for the oxygen reduction reaction, Micropor. Mesopor. Mater., 278 (2019) 280-288.

[7] L. Yang, S. Jiang, Y. Zhao, L. Zhu, S. Chen, X. Wang, Q. Wu, J. Ma, Y. Ma, Z. Hu, Boron-doped carbon nanotubes as metal-free electrocatalysts for the oxygen reduction reaction, Angew. Chem. Int. Ed., 50 (2011) 7132-7135.

[8] D.S. Yang, D. Bhattacharjya, S. Inamdar, J. Park, J.S. Yu, Phosphorus-doped ordered mesoporous carbons with different lengths as efficient metal-free electrocatalysts for oxygen reduction reaction in alkaline media, J. Am. Chem. Soc., 134 (2012) 16127-16130.

[9] G.A. Ferrero, A.B. Fuertes, M. Sevilla, M.M. Titirici, Efficient metal-free N-doped mesoporous carbon catalysts for ORR by a template-free approach, Carbon, 106 (2016) 179-187.

[10] R. Li, X. Shao, S. Li, P. Cheng, Z. Hu, D. Yuan, Metal-free N-doped carbon nanofibers as an efficient catalyst for oxygen reduction reactions in alkaline and acid media, Nanotechnol., 27 (2016) 505402.

[11] R.P. Rocha, O.S.G. Soares, J.L. Figueiredo, M.F.R. Pereira, Tuning CNT Properties for MetalFree Environmental Catalytic Applications, J. Carbon Res., 2 (2016).

[12] J. Wu, Z. Yang, Q. Sun, X. Li, P. Strasser, R. Yang, Synthesis and electrocatalytic activity of phosphorus-doped carbon xerogel for oxygen reduction, Electrochim. Acta, 127 (2014) 53-60.

[13] Y. Liu, Y.Y. Wu, G.J. Lv, T. Pu, X.Q. He, L.L. Cui, Iron(II) phthalocyanine covalently functionalized graphene as a highly efficient non-precious-metal catalyst for the oxygen reduction reaction in alkaline media, Electrochim. Acta, 112 (2013) 269-278.

[14] N. Ranjbar Sahraie, J.P. Paraknowitsch, C. Göbel, A. Thomas, P. Strasser, Noble-metal-free electrocatalysts with enhanced ORR performance by task-specific functionalization of carbon using ionic liquid precursor systems, J. Am. Chem. Soc., 136 (2014) 14486-14497.

[15] G.A. Ferrero, K. Preuss, A. Marinovic, A.B. Jorge, N. Mansor, D.J. Brett, A.B. Fuertes, M. Sevilla, M.M. Titirici, Fe-N-Doped Carbon Capsules with Outstanding Electrochemical Performance and Stability for the Oxygen Reduction Reaction in Both Acid and Alkaline Conditions, ACS Nano, 10 (2016) 5922-5932.

[16] J. Zheng, C. Guo, C. Chen, M. Fan, J. Gong, Y. Zhang, T. Zhao, Y. Sun, X. Xu, M. Li, R. Wang, Z. Luo, C. Chen, High content of pyridinic- and pyrrolic-nitrogen-modified carbon nanotubes derived from blood biomass for the electrocatalysis of oxygen reduction reaction in alkaline medium, Electrochim. Acta, 168 (2015) 386-393.

[17] D. Geng, Y. Chen, Y. Chen, Y. Li, R. Li, X. Sun, S. Ye, S. Knights, High oxygen-reduction activity and durability of nitrogen-doped graphene, Energy Environ. Sci., 4 (2011) 760-764.

[18] D.G. Gu, R.G. Ma, Y. Zhou, F.F. Wang, K. Yan, Q.A. Liu, J.C. Wang, Synthesis of NitrogenDoped Porous Carbon Spheres with Improved Porosity toward the Electrocatalytic Oxygen Reduction, ACS Sustainable Chem. Eng., 5 (2017) 11105-11116. 
[19] G.A. Ferrero, K. Preuss, A.B. Fuertes, M. Sevilla, M.M. Titirici, The influence of pore size distribution on the oxygen reduction reaction performance in nitrogen doped carbon microspheres, J. Mater. Chem. A, 4 (2016) 2581-2589.

[20] J. Li, X. Qin, P. Hou, M. Cheng, C. Shi, C. Liu, H. Cheng, M. Shao, Identification of active sites in nitrogen and sulfur co-doped carbon-based oxygen reduction catalysts, Carbon, (2019).

[21] L. Lin, Q. Zhu, A.W. Xu, Noble-metal-free Fe-N/C catalyst for highly efficient oxygen reduction reaction under both alkaline and acidic conditions, J. Am. Chem. Soc., 136 (2014) 11027-11033.

[22] R.G. Morais, N. Rey-Raap, J.L. Figueiredo, M.F.R. Pereira, Glucose-derived carbon materials with tailored properties as electrocatalysts for the oxygen reduction reaction, Beilstein J. Nanotechnol., 10 (2019) 1089-1102.

[23] I.M. Rocha, O.S.G.P. Soares, D.M. Fernandes, C. Freire, J.L. Figueiredo, M.F.R. Pereira, Ndoped Carbon Nanotubes for the Oxygen Reduction Reaction in Alkaline Medium: Synergistic Relationship between Pyridinic and Quaternary Nitrogen, ChemistrySelect, 1 (2016) 2522-2530. [24] K. Parvez, S. Yang, Y. Hernandez, A. Winter, A. Turchanin, X. Feng, K. Mullen, Nitrogen-doped graphene and its iron-based composite as efficient electrocatalysts for oxygen reduction reaction, ACS Nano, 6 (2012) 9541-9550.

[25] C. Guo, Y. Wu, Z. Li, W. Liao, L. Sun, C. Wang, B. Wen, Y. Li, C. Chen, The Oxygen Reduction Electrocatalytic Activity of Cobalt and Nitrogen Co-doped Carbon Nanocatalyst Synthesized by a Flat Template, Nanoscale Res. Lett., 12 (2017) 144-144.

[26] S.J. Taylor, M.D. Haw, J. Sefcik, A.J. Fletcher, Gelation mechanism of resorcinolformaldehyde gels investigated by dynamic light scattering, Langmuir, 30 (2014) 10231-10240.

[27] S.A. Al-Muhtaseb, J.A. Ritter, Preparation and properties of resorcinol-formaldehyde organic and carbon gels, Adv. Mater., 15 (2003) 101-114.

[28] R.W. Pekala, Organic aerogels from the polycondensation of resorcinol with formaldehyde, J. Mater. Sci., 24 (1989) 3221-3227.

[29] N. Rey-Raap, J. Angel Menéndez, A. Arenillas, Simultaneous adjustment of the main chemical variables to fine-tune the porosity of carbon xerogels, Carbon, 78 (2014) 490-499.

[30] M. Canal-Rodríguez, J.A. Menéndez, A. Arenillas, Carbon Xerogels: The Bespoke Nanoporous Carbons, Porosity - Process, Technologies and Applications, IntechOpen2018, pp. 69-89.

[31] M. Canal-Rodríguez, J.A. Menéndez, M.A. Montes-Morán, A. Arenillas, The relevance of conductive additive addition methodology for optimizing the performance of electrodes based on carbon xerogels in aqueous supercapacitors, J. Electroanal. Chem., 836 (2019) 45-49.

[32] M. Canal-Rodriguez, A. Arenillas, J.A. Menendez, D. Beneroso, N. Rey-Raap, Carbon xerogels graphitized by microwave heating as anode materials in lithium-ion batteries, Carbon, 137 (2018) 384-394.

[33] N. Rey-Raap, E.G. Calvo, J.M. Bermúdez, I. Cameán, A.B. García, J.A. Menéndez, A. Arenillas, An electrical conductivity translator for carbons, Measurement, 56 (2014) 215-218. 